Clinical Paper

\title{
MRSA biofilm-producer chronic osteomielitis in a diabetic patient successfully treated with antimicrobial monotherapy
}

\section{Clinical paper}

We presented in a schematized way a clinical case of a diabetic patient with severe chronic osteomyelitis that involves the microbiological diagnosis and therapeutic management that ends in the health restitution after the treatment.

\section{Clinical relevant information}

M.P. is a male, 75 years old with 5 important morbidities:

i. Coronary heart disease with 2 bypass surgeries +2 stents $(2005$ \& 2006).

ii. Insulin-dependent diabetic.

iii. Severe fatty liver.

iv. Mild obstructive peripheric arteriopathy.

v. COPD (emphysema pattern).

Polymedicated for all the mentioned pathologies. He comes to the Medical Microbiology Unit in January 2010 with a chronic right pretibial ulcer of 7 years of evolution that increased size in the previous year and presents in the bottom one fistula and purulent discharge, severe pain and limitation for walking.

The microbiological isolates, treatments \& clinical evolution (partial outcome) at different medical facilities for the previous 7 years to the Medical Microbiology

Unit intervention was the following:

\begin{tabular}{|l|l|}
\hline 2005 & $\begin{array}{l}\text { June: MRSA - Clindamycin (14 days) - Improvement } \\
\text { - September: MRSA - Trimethoprim/sulfamethoxazole (21 days) - } \\
\text { Improvement }\end{array}$ \\
\hline
\end{tabular}

MSSA: Methicillin-Sensible Staphylococcus aureus, EFA: Enterococcus faecalis

$2004 \begin{aligned} & \text { - July: PAE - Ciprofloxacin + Silver dressing (14 days) - Improvement } \\ & \text { - December: PAE - Levofloxacin (10 days) - Improvement }\end{aligned}$

PAE: Pseudomonas aeruginosa

$2003 \begin{aligned} & \text { - March: MSSA - Clindamycin (14 days) - Improvement } \\ & \text { July: EFA - Ampicillin (10 days) - Improvement } \\ & \text { - November: MSSA - Trimethoprim/sulfamethoxazole (21 days) - } \\ & \text { Improvement }\end{aligned}$

MRSA: Methicillin-Resistant Staphylococcus aureus

$\left.\begin{array}{c}2006- \\ 2008\end{array}\right]$."Asymptomatic"

S. haemolyticus MR: Staphylococcus haemolyticus MethicillinResistant

In January 2010, the patient comes to Angios Vascular Centre and was referred to the Medical Microbiology Unit for clinical \& microbiological evaluation for the expert physician in Medical
Volume 4 Issue 2 - 2017

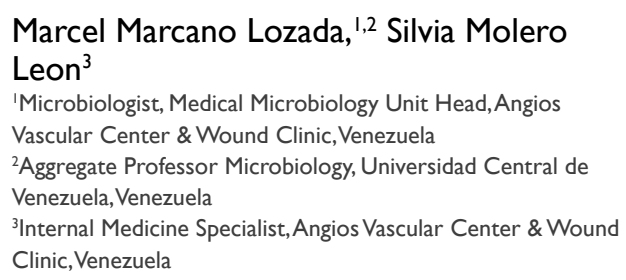

Correspondence: Marcel Marcano-Lozada, Medical Microbiology Unit, Angios Vascular Center \& Wound Clinic, Caracas,Venezuela, Email marcelmarcano@gmail.com

Received: February 14, 2017| Published: March 01, 2017

Microbiology, and the multidisciplinary approach for different specialties. The microbiological isolates, treatments \& clinical evolution in the year 2010 were the following:
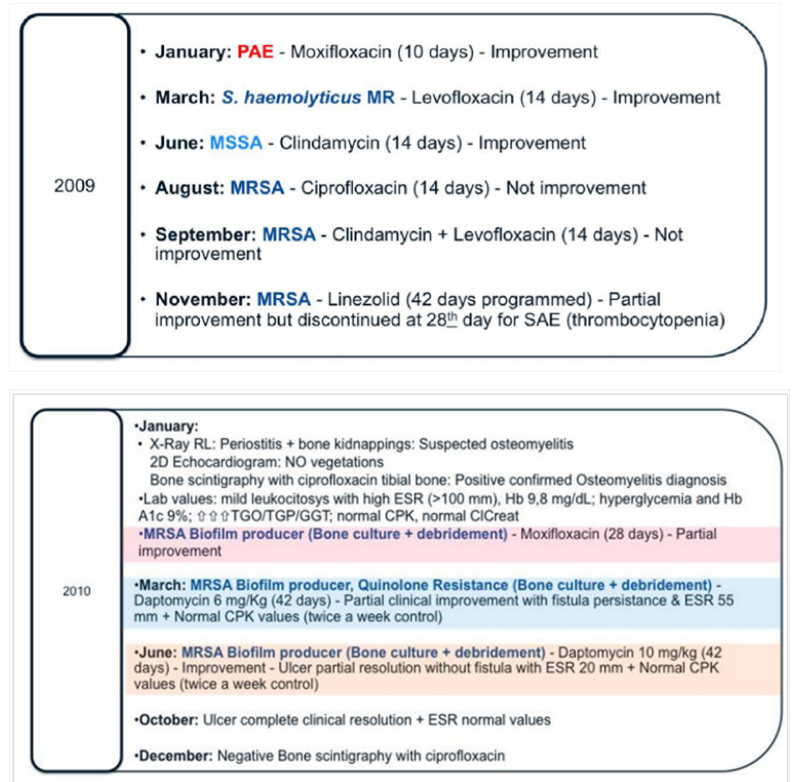

ESR: Erythrocyte Sedimentation Rate, HbA1c: Glycohemoglobin, CPK: Creatine PhosphoKinase, ClCreat: Creatinine Clearance

We present in detail the antimicrobial susceptibility patterns from the three MRSA isolates of right tibial bone samples obtained during the treatment: (Table 1).

* Susceptibility to Vancomycin and Daptomycin was performed by the E-test method, for the remaining antimicrobials were performed by the disc diffusion method. 
Table I Susceptibility Repot

\begin{tabular}{llll}
\hline Antibiotic & January & March & June \\
\hline pencillin & Susceptibility Repot & & \\
Oxacillin & $\mathrm{R}$ & $\mathrm{R}$ & $\mathrm{R}$ \\
Erithromycin & $\mathrm{R}$ & $\mathrm{R}$ & $\mathrm{R}$ \\
Clindamycin & $\mathrm{R}$ & $\mathrm{R}$ & $\mathrm{R}$ \\
Ciprofloxacin & $\mathrm{R}$ & $\mathrm{R}$ & $\mathrm{R}$ \\
Gentamicin & $\mathrm{S}$ & $\mathrm{S}$ & $\mathrm{S}$ \\
Trimethoprism-sulfamethoxazole & $\mathrm{S}$ & $\mathrm{S}$ & $\mathrm{S}$ \\
Rifampin & $\mathrm{S}$ & $\mathrm{S}$ & $\mathrm{S}$ \\
Quinupristin/dalfopristin & $\mathrm{S}$ & $\mathrm{S}$ & $\mathrm{S}$ \\
Teicoplanin & $\mathrm{S}$ & $\mathrm{S}$ & $\mathrm{S}$ \\
Linezolid & $\mathrm{S}$ & $\mathrm{S}$ & $\mathrm{S}$ \\
Vancomycin & $\mathrm{S}$ & $\mathrm{S}$ & $\mathrm{S}$ \\
Daptomycin & $\mathrm{SI}, 5 \mu \mathrm{g} / \mathrm{mL}$ & $\mathrm{S} 1,5 \mu \mathrm{g} / \mathrm{mL}$ & $\mathrm{S} / \mu \mathrm{g} / \mathrm{mL}$ \\
\hline
\end{tabular}

S, Susceptible; R, Resistant

The successful one-year follow-up clinical outcome:

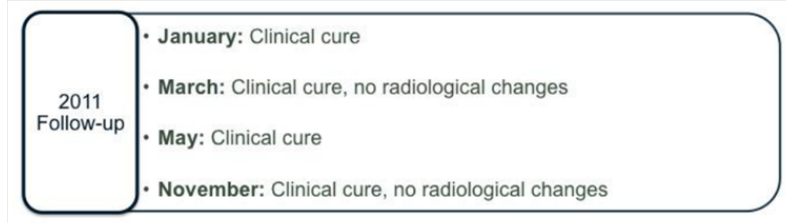

At next five-year follow-up the successful clinical outcome remains:

\begin{tabular}{|l|l|} 
Five year & $\begin{array}{l}\text { 2012: Asymptomatic, No radiological changes } \\
\text { Follow-up } 2013: \text { Asymptomatic, No radiological changes } \\
\cdot 2014: \text { Asymptomatic, No radiological changes } \\
\cdot 2015: \text { Asymptomatic, No radiological changes } \\
\text { 2016: Asymptomatic, No radiological changes }\end{array}$ \\
\hline
\end{tabular}

\section{Commentary}

The correct diagnosis of the etiology of chronic osteomyelitis in an elderly patient, severely ill and with multiple treatment failures, can guide anti-infective therapy to achieve bone eradication of bacterial infection.

In the case at hand, the appropriate surgical intervention with a broad osteotomy in the required opportunities (three times), which also allowed the microorganism to be identified and could continue to be directed, and rotating antimicrobial therapy, since the emergence of resistance to wuinolones resulted in the choice of Daptomycin at doses similar to those used in bacteremia for 6 weeks $(6 \mathrm{mg} / \mathrm{Kg})$, and subsequently allowed to define the escalation of doses of Daptomycin at $10 \mathrm{mg} / \mathrm{Kg}$ for a further 6 weeks, without any adverse events during this treatment. At the time of this intervention, the escalation monotherapy with Daptomycin has no many reported experience, and de-escalation generally was associated with muscle or nephrotoxicity.

All the anti-infective therapy was intravenous administered in the ambulatory setting know as OPAT (Outpatient Parenteral Antimicrobial Therapy), in a special unit dedicated to the one-daily administration of the medication, in order to avoid hospitalization and its complications, and reducing costs based on a pharmacoeconomic model in addition, the patients daily routine was not affected.

At follow-up at the first year and then at the following five years, clinical and radiological cure is maintained, with no bone changes or fistulas or pain in the affected limb.

It is noteworthy that in our case, the patient was not a candidate to use combination therapy because of the liver disease he presented and, in addition, the expected drug interactions complicated the use of combination therapy that could have eliminated the biofilm-producing microorganism much more early. In special situations such as this, it is demonstrated that the use of long-term high-potency monotherapy can achieve the cure of osteomyelitis (including that caused by biofilm-producing bacteria) and return an adequate quality of life to the patient.

\section{Conflicts of Interest}

The authors declare no conflict of interest.

\section{Acknowledgments}

None.

\section{Funding}

None. 